\title{
Elisabeth Vigée Le Brun, Souvenirs 1755-1842
}

\section{Regina Bochenek-Franczakowa}

\section{(2) OpenEdition}

\section{Journals}

Édition électronique

URL : http://journals.openedition.org/studifrancesi/7953

DOI : 10.4000/studifrancesi.7953

ISSN : 2421-5856

\section{Éditeur}

Rosenberg \& Sellier

\section{Édition imprimée}

Date de publication : 1 juillet 2009

Pagination : 406

ISSN : 0039-2944

\section{Référence électronique}

Regina Bochenek-Franczakowa, «Elisabeth Vigée Le Brun, Souvenirs 1755-1842 », Studi Francesi [En ligne], 158 (LIII | II) | 2009, mis en ligne le 30 novembre 2015, consulté le 08 janvier 2021. URL : http:// journals.openedition.org/studifrancesi/7953; DOI : https://doi.org/10.4000/studifrancesi.7953

Ce document a été généré automatiquement le 8 janvier 2021.

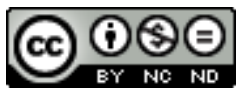

Studi Francesi è distribuita con Licenza Creative Commons Attribuzione - Non commerciale - Non opere derivate 4.0 Internazionale. 


\title{
Elisabeth Vigée Le Brun, Souvenirs 1755-1842
}

\author{
Regina Bochenek-Franczakowa
}

\section{RÉFÉRENCE}

ELISABETH VIGÉE LE BRUN, Souvenirs 1755-1842, texte établi, présenté et annoté par

Geneviève HAROCHE-BOUZINAC, Paris, Champion («Bibliothèque des Correspondances, Mémoires et Journaux» 42), 2008, pp. 852.

1 Les Souvenirs d'Élisabeth Vigée Le Brun, dont Geneviève Haroche-Bouzinac livre la première édition critique, nous mettent en présence d'une personnalité exceptionnelle. Peintre célèbre, portraitiste des plus grands monarques et de l'élite aristocratique de l'Europe des Lumières, membre des académies de Parme, Genève, Saint-Pétersbourg, Mme Vigée Le Brun illustre une destinée peu commune pour la femme du XVIII ${ }^{\mathrm{e}}$ siècle : elle se fraie la voie à la célébrité et réussit à se procurer l'autonomie, même économique, par sa création artistique.

Dans son ample «Introduction» (pp. 7-120), G. Haroche Bouzinac met l'accent sur divers aspects de l'ouvrage: tout d'abord, sur le caractère hybride des Souvenirs qui se situent «à mi-chemin des mémoires et de l'autobiographie» (p. 7). Le recueil se compose, en effet, des souvenirs en forme épistolaire (le récit de l'enfance et de la jeunesse est contenu dans 12 lettres à la princesse Kourakina, le voyage en Suisse des années 1808-09 est relaté dans les lettres à la comtesse Potocka) et d'une narration adressée au lecteur virtuel (35 chapitres). De plus, le récit de vie est truffé d'anecdotes, portraits, mais encore, de lettres et poèmes reçus par l'autobiographe. On y trouve aussi des listes d'œuvres réalisées à diverses étapes de la vie, dressées par Élisabeth Vigée Le Brun ellemême ainsi que, placé à la fin du volume, le texte de Conseils sur la peinture du portrait destiné aux femmes qui apprennent à peindre. G. Haroche-Bouzinac attire l'attention sur différents problèmes liés à la vie de la femme-artiste, sa formation persévérante qui 
lui fait éviter le piège du dilettantisme, les rapports: peintre-prince commanditaire, la dimension psychologique et artistique de la création de Vigée Le Brun.

Il faut souligner l'érudition imposante de l'auteur de cette édition, dont témoignent les innombrables notes: toutes les personnes rencontrées, tous les lieux parcourus par l'artiste sont identifiés et dotés d'une caractéristique. C'est un guide inestimable pour le lecteur qui suit la célèbre femme peintre dans ses nombreux voyages à travers toute l'Europe (l'Italie, Berlin, Vienne, Saint-Pétersbourg, Moscou, Londres, la Suisse). La lecture des mémoires d'Élisabeth Vigée Le Brun reporte le lecteur moderne à l'époque mouvementée et mémorable du tournant des Lumières sur laquelle l'artiste pose «un regard du peintre» qui «se superpose à celui de la mémorialiste» (p. 13) Encore plus que du récit de vie, ces «souvenirs» sont remplis de portraits d'autrui, de paysages, de descriptions des villes parcourues, des musées et des galeries visités par la femme peintre. Celle-ci fait preuve de sensibilité et de sens d'observation; elle scrute les visages aussi attentivement que les mœurs des pays et des villes où elle a vécu plusieurs années (Italie, Russie, Vienne, Londres). Partout où elle voyage, elle retrouve des amis ou s'en fait de nouveaux: Mme Vigée Le Brun appartenait bel et bien à «l'Europe des Lumières».

4 Selon la formule heureuse de G. Haroche-Bouzinac, «la lumière qui se dégage» des souvenirs d'Élisabeth Vigée Le Brun «n'est pas celle des Lumières de la raison, mais celle de la fraîcheur des coloris de sa palette et de la grâce de son regard» (p. 9). C'est que, comme l'a avoué l'artiste, «peindre et vivre n'a jamais été qu'un seul et même mot pour [elle]» (p. 438). 